\title{
Low expression of secreted frizzled-related protein 2 and nuclear accumulation of $\beta$-catenin in aggressive nonfunctioning pituitary adenoma
}

\author{
YOUTU WU ${ }^{1}$, JIWEI BAI ${ }^{2}$, LINCHUAN HONG ${ }^{1}$, CHUNHUI LIU ${ }^{1}$, \\ SHENGYUAN YU ${ }^{1}$, GUOQIANG YU ${ }^{1}$ and YAZHUO ZHANG ${ }^{1}$ \\ ${ }^{1}$ Department of Neurosurgery, Beijing Neurosurgical Institute; ${ }^{2}$ Department of Neurosurgery, Beijing Tiantan Hospital, \\ Capital Medical University, Beijing 100050, P.R. China
}

Received January 15, 2015; Accepted April 15, 2016

DOI: $10.3892 / \mathrm{ol} .2016 .4560$

\begin{abstract}
The identification of a specific molecular marker for aggressiveness of nonfunctioning pituitary adenomas (NFPAs) is urgently required in order to guide the clinical diagnosis and treatment of NFPAs. In the present study, low expression of secreted frizzled-related protein 2 (sFRP2) in NFPAs was demonstrated by reverse transcription-quantitative polymerase chain reaction, western blot and immunohistochemical analyses. The results confirmed an abnormal accumulation of free $\beta$-catenin in the nuclei of NFPAs, which is the core step for the activation of the Wnt canonical signaling pathway. Furthermore, cyclin D1 and c-Myc, the downstream proteins of the Wnt canonical signaling pathway, were overexpressed in aggressive NFPAs. These findings demonstrated the activation of the Wnt canonical signaling pathway in aggressive NFPAs. In addition, sFRP2 expression was observed to be inversely correlated to the aggressiveness of NFPAs. Therefore, sFRP2 may act as a tumor suppressor through modulation of the cellular cytosolic pool of $\beta$-catenin in NFPAs. Furthermore, the expression of sFRP2 may serve as a biomarker for NFPAs aggressiveness and prognosis.
\end{abstract}

\section{Introduction}

Pituitary adenoma is the third most frequently diagnosed of all intracranial tumors, comprising $\sim 10-25 \%$ of all

Correspondence to: Professor Yazhuo Zhang, Department of Neurosurgery, Beijing Neurosurgical Institute, Capital Medical University, 6 Tiantan Xili, Dongcheng, Beijing 100050, P.R. China E-mail: zyz2004520@yeah.net

Abbreviations: sFRPs, secreted frizzled-related proteins; NFPAs, nonfunctioning pituitary adenomas; PCR, polymerase chain reaction; IHC, immunohistochemistry; CT, computed tomography; MRI, magnetic resonance imaging; GAPDH, glyceraldehyde-3-phosphate dehydrogenase

Key words: secreted frizzled-related protein 2, nonfunctioning pituitary adenoma, $\beta$-catenin, Wnt canonical signaling pathway intracranial tumors (1). Human clinically nonfunctioning pituitary adenomas (NFPAs) are defined as adenomas lacking symptoms or signs secondary to oversecretion of pituitary hormones by the tumor (2). NFPAs constitute $9-50 \%$ of all pituitary tumors and $\sim 80 \%$ of all pituitary macroadenomas (3). Effective medical therapy has been demonstrated in FPAs (4). By contrast, for NFPAs, surgery is the first-line treatment (2). However, aggressive NFPAs are not always amenable to complete resection, and radiotherapy should be considered for residual tumors (5). Current detection strategies for pituitary adenoma do not reliably detect the disease at an early stage, and are unable to distinguish between aggressive and non-aggressive pituitary adenoma; thus, effective prognosis and treatment guidance are missing (6,7). At present, the extent of adenoma aggressiveness is mainly determined by computed tomography (CT) and magnetic resonance imaging (MRI) (8). However, the current standards to determine tumor aggressiveness are questioned by numerous scholars, and the effectiveness of the above techniques remains to be determined $(6,7,9)$. Therefore, specific molecular markers for aggressiveness of NFPAs will be more helpful to guide the clinical diagnosis and treatment of aggressive NFPAs.

Wnt signaling is involved in cell fate, proliferation, polarity and death $(10,11)$. Aberrant regulation of the Wnt signaling pathway has been suggested to be involved in tumorigenesis (12). Three intracellular pathways are known to induce Wnt signaling: i) The Wnt- $\beta$-catenin signaling pathway, in which Wnt signaling alters transcription, and it is referred to as 'canonical' Wnt signaling (13); ii) the Wnt- $\mathrm{Ca}^{2+}$ signaling pathway; and iii) the Wnt-c-Jun N-terminal kinase signaling pathway, which do not involve the nucleus or transcription, but rather drive cytoplasmic changes involving the actin cytoskeleton and intracellular calcium stores. Activation of the Wnt- $\beta$-catenin signaling pathway results in the accumulation of free $\beta$-catenin in the nucleus (14). This in turn activates various transcription factors such as T-cell factor to induce the expression of target genes that participate in cell proliferation, including c-Myc and cyclin D1 (14). The Wnt canonical signaling pathway has been studied most extensively in cancer, but it has also been implicated as an important contributor to the pathogenesis of other human diseases (15). 
Recent evidence suggests that soluble extracellular Wnt antagonists regulate Wnt signaling (16). One class of such antagonists is the secreted frizzled-related protein (sFRP) family (16). The expression levels of sFRPs are inversely correlated with the grade and invasive ability of different tumors, including prostate, ovarian and cervical cancer, which suggests that sFRPs activities are fundamental for tissue homeostasis (17-22).

In the present study, it was hypothesized that sFRP2 was downregulated and functioned as a tumor suppressor gene in NFPAs. To address this issue, the messenger (m)RNA and protein expression levels of sFRP2 were compared in non-aggressive NFPAs, aggressive NFPAs and normal pituitary tissues. In addition, the present study investigated whether the Wnt canonical signaling pathway was activated in NFPAs, and examined the association between sFRP2 and the Wnt canonical signaling pathway.

\section{Materials and methods}

Sample collection. Informed consent was obtained from all patients participating in the present study, which was approved by the Ethics Committee of Beijing Tiantan Hospital (Beijing, China).

Between January 2010 and December 2013, 50 NFPA cases (age range, 15-68 years) were obtained from the Beijing Tiantan Hospital. The samples were classified into three groups: Normal pituitary control group, non-aggressive NFPA group and aggressive NFPA group. The diagnosis was based on MRI/CT. Aggressive adenomas were defined as fulfilling one of the following conditions: i) Hardy classification grades III and IV (23); and/or ii) Knosp classification grades III and IV (24). There were 30 non-aggressive NFPAs and 20 aggressive NFPAs. In the non-aggressive group, there were 12 female cases and 18 male cases, whose median age was 42 years. In the aggressive group, there were 7 female cases and 13 male cases, whose median age was 45 years. Tumors were removed by transsphenoidal surgery and immediately 'flash-frozen' in liquid nitrogen until used. Suitable parts of each sample were embedded in paraffin.

The 10 normal pituitary glands were obtained from a donation program between February 2010 and October 2013 in the Beijing Tiantan Hospital (patient age range, 21-45 years). All donors had succumbed to non-neurological diseases. The 10 samples were rinsed in sterile saline and snap-frozen in liquid nitrogen. Suitable parts of each normal pituitary tissue were embedded in paraffin.

All samples were analyzed by reverse transcription-quantitative polymerase chain reaction (RT-qPCR). A total of 15 aggressive and 20 non-aggressive NFPA specimens were randomly selected for western blot analysis, while 10 aggressive and 10 non-aggressive NFPA paraffin specimens were randomly selected for immunohistochemical (IHC) analysis.

IHC analysis. Sections (5- $\mu$ m-thick) were prepared from the formalin-fixed paraffin-embedded blocks. Briefly, slides were deparaffinized, rehydrated in xylene and subjected to an alcohol gradient, and subsequently incubated with anti-sFRP2 (rabbit polyclonal; 1:100 dilution; ab86379;
Abcam, Cambridge, UK) and anti- $\beta$-catenin (rabbit monoclonal; 1:100 dilution; ab32572; Abcam) antibodies overnight at $4^{\circ} \mathrm{C}$. The slides were then incubated for $45 \mathrm{~min}$ at room temperature with anti-rabbit immunoglobulin $\mathrm{G}$ antibody conjugated with horseradish peroxidase-labeled polymer (EnVision $^{\mathrm{TM}}+$ System; Dako, Glostrup, Denmark). Slides were counterstained with hematoxylin and then examined under a light microscope.

Staining for sFRP 2 and $\beta$-catenin was quantified according to the percentage of positive cells (25). Slides were scored by two pathologists (Department of Pathology, Beijing Neurosurgical Institute, Beijing, China) who were blinded to the patients' characteristics. In case of disagreement, the status was determined by consensus following simultaneous dual reexamination.

$R T-q P C R$. Total RNA was isolated from frozen pituitary adenomas and normal pituitaries (100-150 mg) using TRIzol (15596-026; Invitrogen; Thermo Fisher Scientific, Inc., Waltham, MA, USA). RT-qPCR analysis was performed on an ABI 7500 Real-Time system (Applied Biosystems, Foster City, CA, USA), with the following conditions: $50^{\circ} \mathrm{C}$ for $2 \mathrm{~min}, 95^{\circ} \mathrm{C}$ for $10 \mathrm{~min}$, and 40 cycles each at $95^{\circ} \mathrm{C}$ for $15 \mathrm{sec}$ and $60^{\circ} \mathrm{C}$ for $1 \mathrm{~min}$. The housekeeping gene glyceraldehyde-3-phosphate dehydrogenase (GAPDH) was used as an internal control. Relative quantification of gene expression was determined using the $2^{-\Delta \Delta C T}$ method, as described by Livak and Schmittgen (26). The primers used in the RT-qPCR assay were as follows: sFRP2, forward 5'-AGG ACAACGACCTTTGCATC-3' and reverse 5'-TTTGCAGGC TTCACATACCTT-3'; $\beta$-catenin, forward 5'-GAGAATTCA TGTCTGAGGACAAGCCA-3' and reverse 5'-GACTCGAGG GATCCTTACAGGTCAGTATCAAACCAGGC-3'; dishevelled segment polarity protein 3 (DVL-3) forward 5'-AAC CAGGGGGTTATGATAGCTC-3' and reverse 5'-TATCTC CTGGCTCGATGCGTCC-3'; c-Myc forward 5'-TTCGGG TAGTGGAAAACCAG-3' and reverse 5'-CAGCAGCTC GAATTTCTTCC-3'; cyclin D1 forward 5'-AACTACCTG GACCGCTTCCT-3' and reverse 5'-CCACTTGAGCTTGTT CACCA-3'; and GAPDH forward 5'-ACCACAGTCCATGCC ATCACT-3' and reverse 5'-GTCCACCACCCTGTTGCT GTA-3'. The specificity of the PCR products was verified by performing dissociation reaction plots.

Protein extraction and western blot analysis. Western blotting was performed according to published methods (27). Blots were incubated with the primary antibody overnight at $4^{\circ} \mathrm{C}$. The primary antibodies used were as follows: Rabbit polyclonal anti-GAPDH (1:1,000; G9545; Sigma-Aldrich, St. Louis, MO, USA), rabbit monoclonal anti- $\beta$-catenin $(1: 5,000$; ab32572; Abcam), rabbit polyclonal anti-sFRP2 (1:5,000; ab86379; Abcam), rabbit monoclonal anti-cyclin D1 (1:1,000; ab40754; Abcam), rabbit monoclonal anti-DVL-3 (1:1,000; ab76081; Abcam) and rabbit monoclonal anti-c-Myc (1:1,000; ab32072; Abcam). Horseradish peroxidase-conjugated secondary antibody was next added (1:5,000; SI-B5645; Sigma-Aldrich) for $1 \mathrm{~h}$ at room temperature, followed by enhanced chemiluminescence development (GE Healthcare Life Sciences, Chalfont, UK). The final data were subjected to grayscale scanning and semi-quantitative analysis using 
A

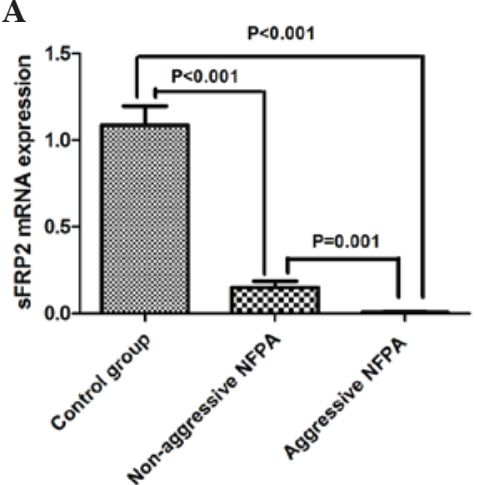

B

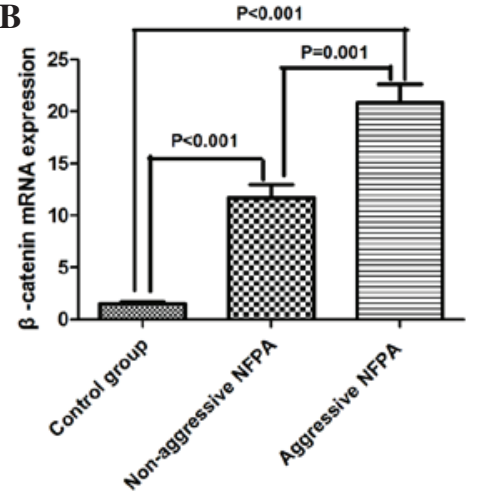

C

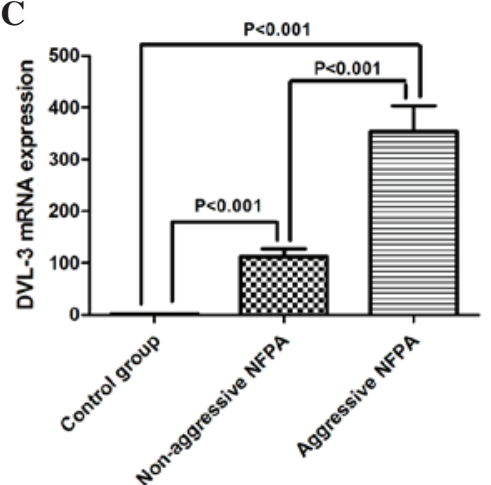

D

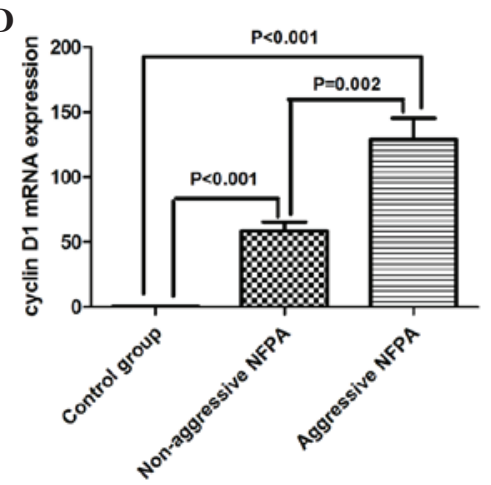

$\mathbf{E}$

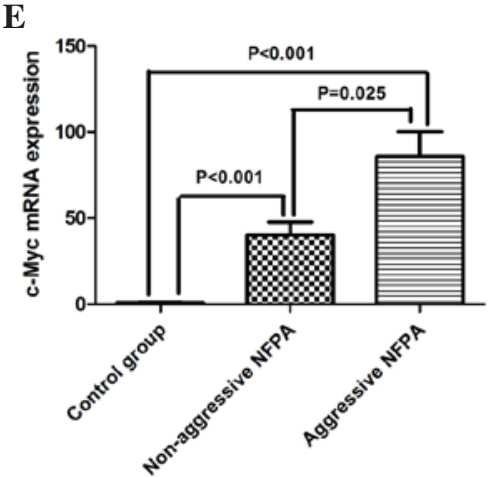

Figure 1. Relative messenger RNA expression of (A) secreted frizzled-related protein 2, (B) $\beta$-catenin, (C) dishevelled segment polarity protein 3, (D) cyclin D1 and (E) c-Myc were assessed by reverse transcription-quantitative polymerase chain reaction in normal pituitary tissues, non-aggressive NFPAs and aggressive NFPAs. Data are presented as the mean \pm standard error of the mean. sFRP2, secreted frizzled-related protein 2; mRNA, messenger RNA; DVL-3, dishevelled segment polarity protein 3 ; NFPA, nonfunctioning pituitary adenoma.

Quantity One 4.62 software (Bio-Rad Laboratories, Inc., Hercules, CA, USA).

Nuclear proteins were extracted using a Nuclear Extraction Kit (KA1346; Abnova, Taipei City, Taiwan), according to the manufacturer's protocol $(28,29)$. The nuclear protein extract was analyzed by western blotting using antibodies against $\beta$-catenin (1:5,000; ab32572; Abcam). Anti-lamin (1:3,000; ab16048; Abcam) was used as a nuclear internal control, while anti- $\alpha$-tubulin (1:4,000; ab15246; Abcam) was used to rule out contamination of cytosolic $\beta$-catenin.

Statistical analysis. All data are expressed as the mean \pm standard error of the mean. Statistical analyses were performed using Student's $t$-tests or non-parametric Mann-Whitney $\mathrm{U}$ tests (for the results of western blot, RT-qPCR and IHC analyses). One-way analysis of variance was used to compare the differences among the three subgroups. Correlation analyses were performed using the Pearson rank-sum test. $\mathrm{P}<0.05$ was considered to indicate a statistically significant difference. SPSS version 17.0 software (SPSS, Inc., Chicago, IL, USA) was used for statistical analyses.

\section{Results}

SFRP2 is downregulated in aggressive NFPAs. To evaluate the expression of sFRP2 in NFPAs and normal pituitary tissues, quantitative measurements of its mRNAs levels by RT-qPCR were performed (Fig. 1). The mRNA levels of sFRP2 were significantly lower in non-aggressive NFPAs compared with those in normal pituitary tissues $(0.150 \pm 0.035$ vs. $1.090 \pm 0.110$; $\mathrm{n}=30$ vs. $10 ; \mathrm{P}<0.001)$. The $\mathrm{sFRP} 2 \mathrm{mRNA}$ levels in the aggressive NFPA group was even lower, compared with those in non-aggressive NFPAs $(0.006 \pm 0.003$ vs. $0.150 \pm 0.035 ; n=20$ vs. $30 ; \mathrm{P}=0.001$ ) (Fig. $1 \mathrm{~A}$ ).

The protein levels of sFRP2 in the three groups were also evaluated by western blotting (Fig. 2). Aggressive NFPAs exhibited downregulation of sFRP2 protein (Fig. 2A) compared with normal pituitary tissues $(0.73 \pm 0.08$ vs. $2.05 \pm 0.08 ; n=15$ vs. $10 ; \mathrm{P}<0.001)$ and non-aggressive NFPAs $(0.73 \pm 0.08$ vs. $1.00 \pm 0.07 ; \mathrm{n}=15$ vs. $20 ; \mathrm{P}=0.011)$. The relative protein expression of sFRP2 in non-aggressive NFPAs was significantly lower than that in normal pituitary tissues $(1.00 \pm 0.07$ vs. $2.05 \pm 0.08 ; n=20$ vs. $10 ; \mathrm{P}<0.001)$, as indicated in Fig. $2 \mathrm{D}$.

Downregulation of sFRP2 protein levels in NFPAs was also confirmed by IHC staining (Fig. 3A-C). The percentage of sFRP2 ${ }^{+}$cells in non-aggressive NFPAs was significantly lower than that in normal controls (Fig. 3D-F) $(35.5 \pm 4.1 \%$ vs. $83.7 \pm 2.8 \% ; \mathrm{n}=10 ; \mathrm{P}<0.001)$. The percentage of $\mathrm{sFRP} 2^{+}$ cells in aggressive NFPAs was only $12.5 \pm 1.8 \%(\mathrm{n}=10)$, which was significantly lower than that in normal pituitary tissues $(\mathrm{P}<0.001)$ and non-aggressive NFPAs $(\mathrm{P}<0.001)$ (Fig. 3G).

Total $\beta$-catenin is only upregulated in aggressive NFPAs, but nuclear $\beta$-catenin protein levels increase progressively in aggressive and non-aggressive NFPAs. The accumulation of $\beta$-catenin and its nuclear translocation are two hallmarks of canonical Wnt signaling (11). The sFRP family is an antagonist of the Wnt canonical signaling pathway (16). The 

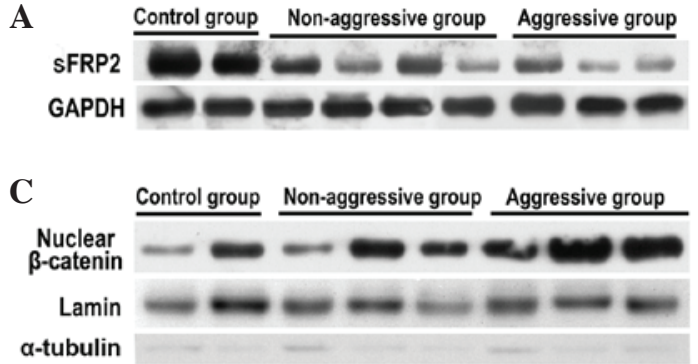
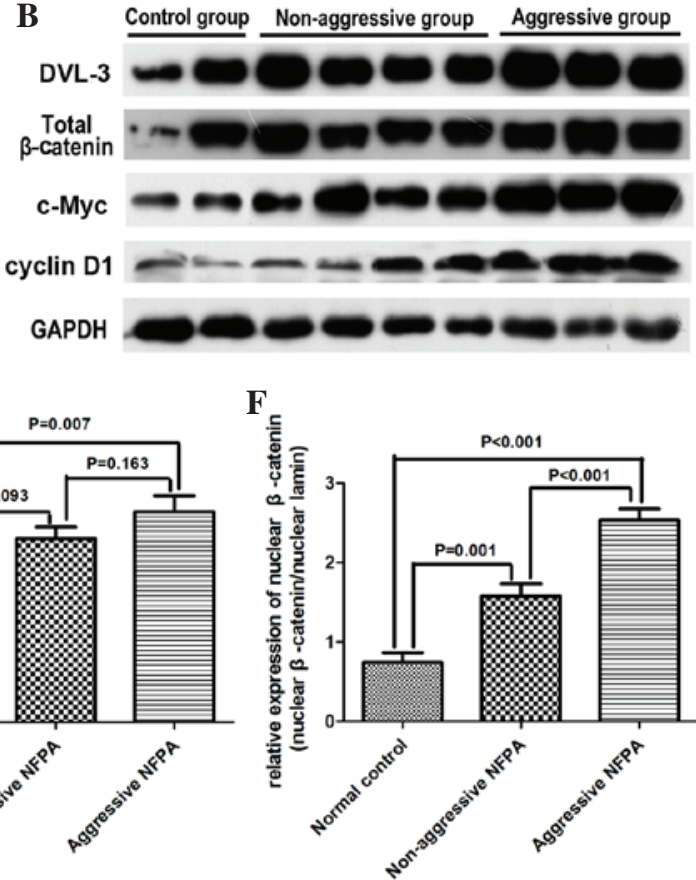

E

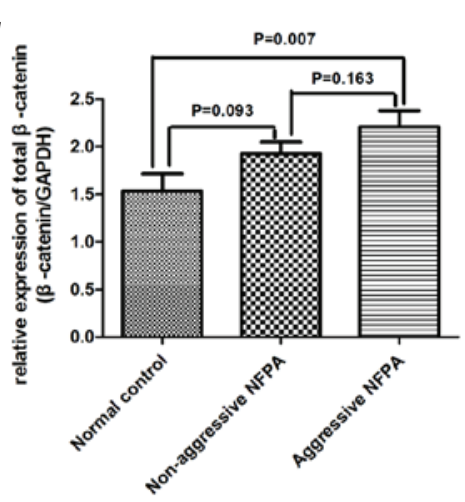

$\mathbf{H}$
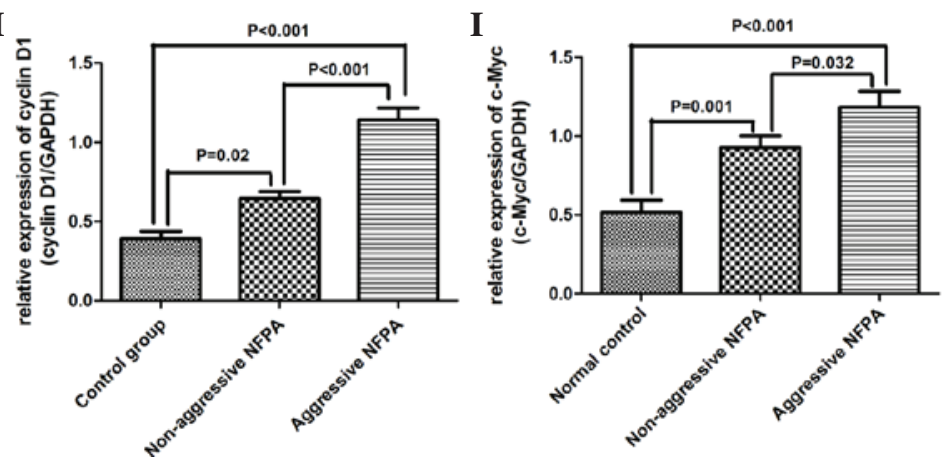

Figure 2. Protein expression in normal pituitary tissues, non-aggressive NFPAs and aggressive NFPAs was detected by western blotting. Expression of the following proteins was measured: (A) Secreted frizzled-related protein 2, (B) total $\beta$-catenin, dishevelled segment polarity protein 3, cyclin D1, c-Myc and (C) nuclear $\beta$-catenin. Quantitative analyses of the western blot results are shown in images D-I. Data are presented as the mean \pm standard error of the mean. sFRP2, secreted frizzled-related protein 2; mRNA, messenger RNA; DVL-3, dishevelled segment polarity protein 3; NFPA, nonfunctioning pituitary adenoma; GAPDH, glyceraldehyde-3-phosphate dehydrogenase.

present RT-qPCR results revealed that the mRNA levels of $\beta$-catenin were significantly upregulated in aggressive and non-aggressive NFPAs, compared with those in normal controls (20.82 \pm 8.06 vs. $1.49 \pm 0.24 ; n=20$ vs. $10 ; \mathrm{P}<0.001$; and $11.68 \pm 1.30$ vs. $1.49 \pm 0.24 ; \mathrm{n}=30$ vs. $10 ; \mathrm{P}<0.001$, respectively) (Fig. 1B), and the difference between non-aggressive and aggressive NFPAs was significant (11.68 \pm 1.30 vs. $20.82 \pm 8.06$; $\mathrm{n}=30$ vs. $20 ; \mathrm{P}=0.001$ ) (Fig. $1 \mathrm{~B}$ ).

Total $\beta$-catenin protein levels in cell lysates were measured by western blotting (Fig. 2B). Consistent with the RT-qPCR results, total $\beta$-catenin protein expression in aggressive NFPAs was higher than that in normal pituitary tissues $(2.21 \pm 0.17 \mathrm{vs}$. $1.54 \pm 0.18 ; \mathrm{n}=15$ vs. $10 ; \mathrm{P}=0.007)$. However, no difference in $\beta$-catenin protein levels between non-aggressive NFPAs and normal pituitary tissues $(1.93 \pm 0.12$ vs. $1.54 \pm 0.18$; $n=20$ vs. 10 ; $\mathrm{P}=0.093$ ), or between non-aggressive and aggressive NFPAs $(1.93 \pm 0.12$ vs. $2.21 \pm 0.17 ; \mathrm{n}=20$ vs. $15 ; \mathrm{P}=0.163)$, was observed (Fig. 2E).

To investigate the nuclear translocation of $\beta$-catenin, the protein levels of nuclear $\beta$-catenin were assessed by western blotting (Fig. 2C). The results revealed that the protein levels of nuclear $\beta$-catenin were higher in non-aggressive NFPAs than in normal pituitary tissues $(1.57 \pm 0.16$ vs. $0.74 \pm 0.12 ; n=20$ vs. $10 ; \mathrm{P}=0.001$ ), and the expression levels were even higher in aggressive NFPAs compared with those in non-aggressive NFPAs $(2.53 \pm 0.15$ vs. $1.57 \pm 0.16 ; \mathrm{n}=15$ vs. $20 ; \mathrm{P}<0.001)$, as represented in Fig. 2F.

Protein expression of $\beta$-catenin was also detected by IHC. The percentage of $\beta$-catenin ${ }^{+}$cells in non-aggressive NFPAs was higher than that in normal control tissues, but this difference was not significant $(25.20 \pm 3.34 \%$ vs. $17.50 \pm 3.00 \%$; $n=10$; $\mathrm{P}=0.090)$. The percentage of $\beta$-catenin ${ }^{+}$cells in aggressive NFPAs was $52.20 \pm 2.95 \%(n=10)$, which was significantly higher than that in normal pituitary tissues and non-aggressive NFPAs $(\mathrm{P}<0.001)$ (Fig. 3H).

Overexpression of DVL-3, cyclin DI and c-Myc in aggressive NFPAs. The expression of components of the Wnt canonical signaling pathway in NFPAs was next measured by RT-qPCR and western blotting. RT-qPCR demonstrated that the mRNA levels of DVL-3, cyclin D1 and c-Myc were significantly increased in non-aggressive NFPAs compared 

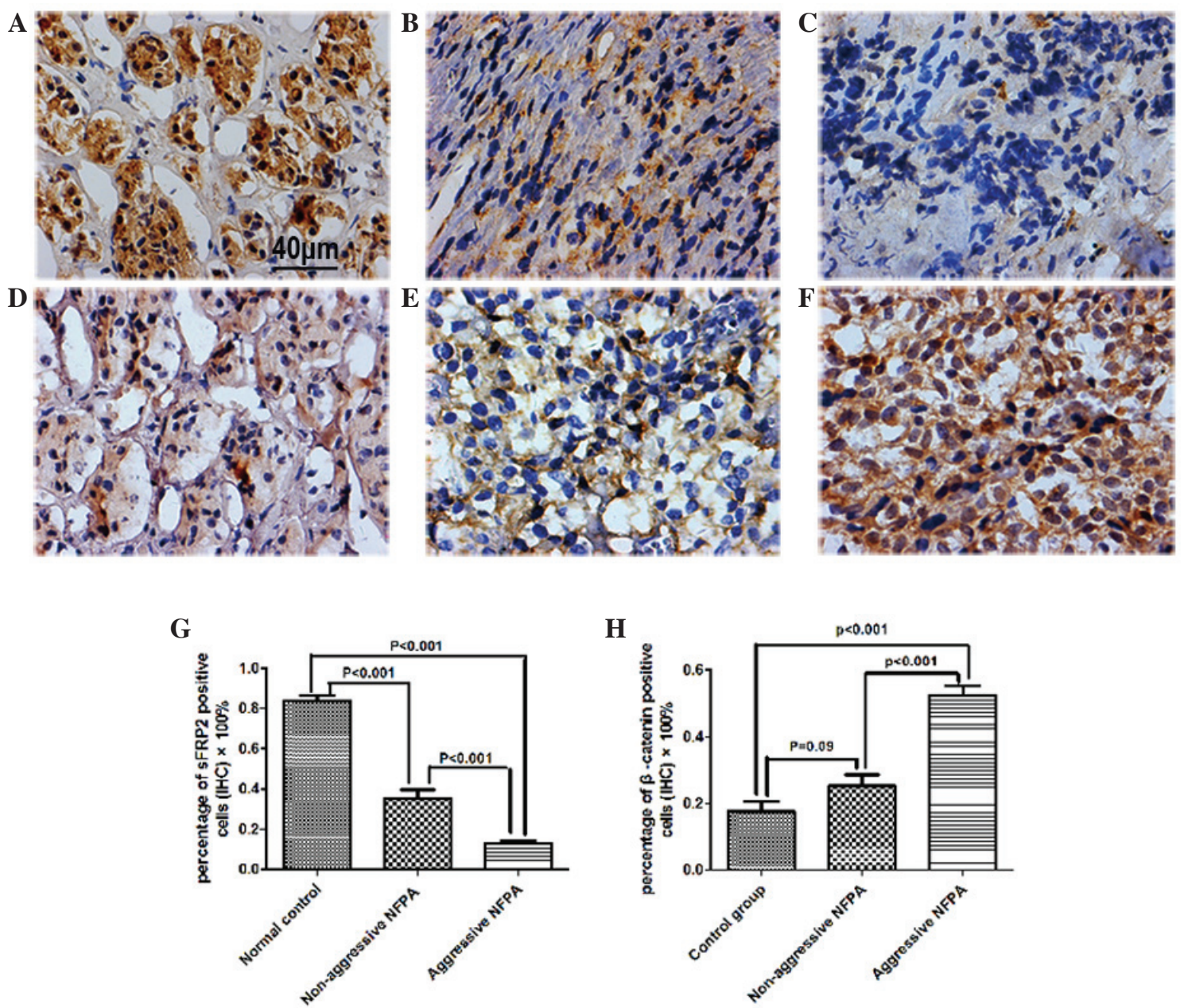

Figure 3. Protein expression was assessed by IHC. sFRP2 ${ }^{+}$cells were detected in (A) normal pituitary tissues, (B) non-aggressive NFPAs and (C) aggressive NFPAs. $\beta$-catenin ${ }^{+}$cells were detected in (D) normal pituitary tissues, (E) non-aggressive NFPAs and (F) aggressive NFPAs. Images G and $\mathrm{H}$ represent the quantitative analysis of IHC for $\mathrm{SFRP}_{2}^{+}$and $\beta$-catenin ${ }^{+}$cells, respectively. Scale bar, $40 \mu \mathrm{m}$. Data are presented as the mean \pm standard error of the mean. sFRP2, secreted frizzled-related protein 2; IHC, immunohistochemistry; NFPA, nonfunctioning pituitary adenoma.

with those in normal pituitary tissues $(112.85 \pm 14.79$ vs. $1.25 \pm 0.29 ; \mathrm{n}=30$ vs. $10 ; \mathrm{P}<0.001 ; 58.61 \pm 6.86$ vs. $0.58 \pm 0.13$; $\mathrm{n}=30$ vs. $10 ; \mathrm{P}<0.001 ;$ and $40.25 \pm 7.57$ vs. $0.94 \pm 0.27 ; \mathrm{n}=30$ vs. 10; $\mathrm{P}<0.001$, respectively). The levels were even higher in aggressive NFPAs compared with those in non-aggressive NFPAs $(354.45 \pm 49.09$ vs. $112.85 \pm 14.79 ; \mathrm{n}=20$ vs. 30 ; $\mathrm{P}<0.001 ; 128.90 \pm 16.30$ vs. $58.61 \pm 6.86 ; \mathrm{n}=20$ vs. $30 ; \mathrm{P}=0.002$; and $85.98 \pm 14.30$ vs. $40.25 \pm 7.57 ; \mathrm{n}=20$ vs. $30 ; \mathrm{P}=0.025$, respectively) (Fig. 1C-E).

The expression of DVL-3, cyclin D1 and c-Myc was also evaluated by western blotting (Fig. 2B). The protein expression levels of DVL-3, cyclin D1 and c-Myc were significantly increased in non-aggressive NFPAs compared with those in normal NFPAs $(1.32 \pm 0.04$ vs. $0.88 \pm 0.08 ; \mathrm{n}=20$ vs. 10 ; $\mathrm{P}<0.001 ; 0.64 \pm 0.04$ vs. $0.39 \pm 0.05 ; \mathrm{n}=20$ vs. $10 ; \mathrm{P}=0.020$; and $0.93 \pm 0.08$ vs. $0.48 \pm 0.08 ; n=20$ vs. $10 ; P=0.001$, respectively). The expression levels of DVL-3 and cyclin D1 were even higher in aggressive NFPAs compared with those in non-aggressive NFPAs ( $1.87 \pm 0.04$ vs. $1.32 \pm 0.04 ; \mathrm{n}=15$ vs. $20 ; \mathrm{P}<0.001$; and $1.14 \pm 0.08$ vs. $0.64 \pm 0.04 ; \mathrm{n}=15$ vs. $20 ; \mathrm{P}<0.001$, respectively) (Fig. 2G-I). In addition, a significant difference in c-Myc expression between non-aggressive and aggressive NFPAs was observed $(0.93 \pm 0.08$ vs. $1.18 \pm 0.10 ; n=20$ vs. $15 ; \mathrm{P}=0.032)$.
Inverse correlation of $S F R P 2$ expression with expression of components of the Wnt canonical signaling pathway in normal pituitary tissues and NFPAs. Western blot analysis of nuclear $\beta$-catenin and components of the Wnt canonical signaling pathway protein revealed that, in contrast to sFRP2, the three groups analyzed exhibited progressively elevated levels of nuclear $\beta$-catenin and components of the Wnt canonical signaling pathway. Linear regression analysis demonstrated a significant negative correlation between the expression of sFRP2 and that of various components of the Wnt canonical signaling pathway $(\mathrm{P}<0.001$; Fig. 4A-D and Table I). Similarly, an inverse correlation was also observed between the percentages of $\mathrm{SFRP}^{+}$and $\beta$-catenin ${ }^{+}$cells by IHC (Pearson's correlation coefficient $r=-0.633 ; n=45 ; 2$-tailed $\mathrm{P}<0.001$ ) (Fig. 4E).

\section{Discussion}

Although NFPA is a type of benign tumor, certain NFPAs may present aggressive characteristics (5). Aggressive NFPAs are difficult to resect completely, which often leads to tumor recrudescence (5). It is therefore important to identify the aggressiveness of NFPAs for selection of the appropriate 
Table I. Correlation analysis between sFRP2 expression and nuclear $\beta$-catenin, DVL-3, cyclin D1 and c-Myc expression in normal pituitary tissues and nonfunctioning pituitary adenomas.

\begin{tabular}{lcccc}
\hline sFRP2 & Nuclear $\beta$-catenin & DVL-3 & Cyclin D1 & c-Myc \\
\hline Pearson's correlation coefficient $r$ & -0.538 & -0.710 & -0.645 & -0.580 \\
P-value (2-tailed) & $<0.001$ & $<0.001$ & $<0.001$ & $<0.001$ \\
Number of samples & 45 & 45 & 45 & 45 \\
\hline
\end{tabular}

sFRP2, secreted frizzled-related protein 2; DVL-3, dishevelled segment polarity protein 3.

A

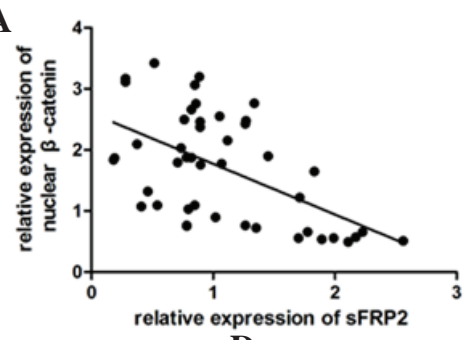

D $\overline{\text { s }}$
B

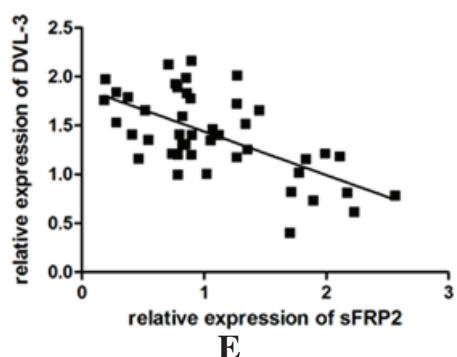

$\mathbf{E}$
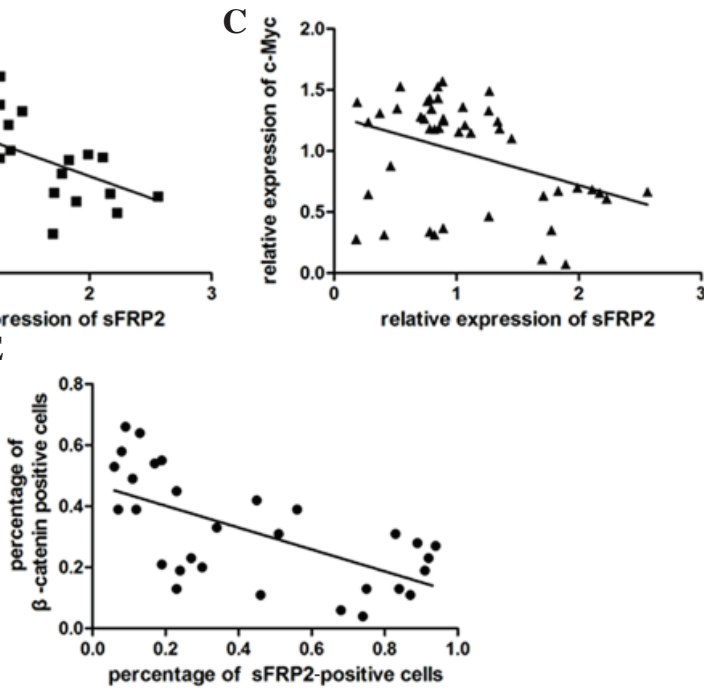

Figure 4. Inverse correlation of sFRP2 expression with the expression of components of the Wnt canonical signaling pathway, presented as scatter diagrams. Correlation analysis of western blot results for the protein expression of sFRP2 and the protein expression of (A) nuclear $\beta$-catenin, (B) dishevelled segment polarity protein 3, (C) cyclin D1 and (D) c-Myc. (E) Correlation analysis of immunohistochemistry results regarding the percentage of sFRP2 ${ }^{+}$and $\beta$-catenin ${ }^{+}$ cells. sFRP2, secreted frizzled-related protein 2; IHC, immunohistochemistry;.DVL-3, dishevelled segment polarity protein 3.

therapy and prognostic evaluation. Recently, the Wnt signaling pathway has been reported to be involved in tumorigenesis in several cell types (30-34). sFRPs have been identified as possible antagonists of the Wnt signaling pathway, and sFRP2, a member of the sFRPs family, has been associated with the degree of tumor malignancy and invasive ability of various types of human cancer $(20,22)$.

The evaluation of sFRP2 as a putative marker of aggressive NFPAs has not been previously reported. In the present study, the IHC results for SFRP2 revealed the highest cytoplasmic sFRP2 expression in normal human pituitary tissues, with strong-to-moderate sFRP2 expression in non-aggressive NFPAs and the lowest sFRP2 expression in aggressive NFPAs. These results were consistent with the present western blot and RT-qPCR results.

Since sFRP2 is an inhibitor of the Wnt signaling pathway, the present study also examined the Wnt canonical signaling pathway in order to understand the mechanism responsible for the association between sFRP2 expression and the invasive ability of NFPAs. Western blot analysis demonstrated that the expression of downstream Wnt signaling proteins, including DVL-3, c-Myc and cyclin D1, was significantly higher in non-aggressive tumor tissues than in normal pituitary tissues, and that the expression of these proteins in aggressive tumors was even higher than that in non-aggressive tumors. Similar trends were also observed at the mRNA level. In addition, the present study conducted for the first time a comparison between the expression levels of nuclear $\beta$-catenin in normal pituitary tissues, non-aggressive NFPAs and aggressive NFPAs by western blotting. The results revealed an abnormal accumulation of free $\beta$-catenin in the nuclei of NFPAs, which is the core step for the activation of the Wnt canonical signaling pathway (13). The expression of $\beta$-catenin was further confirmed by IHC. The present data support the opinion that the Wnt canonical signaling pathway is activated in NFPAs, and is consistent with previous studies (35). However, the present western blotting results of total $\beta$-catenin protein expression indicated that there was no significant difference between normal control and non-aggressive NFPA groups, or between non-aggressive and aggressive NFPA groups. The only significant difference observed was between normal control and aggressive NFPA groups. Therefore, the changes in total $\beta$-catenin levels may not represent the changes in nuclear $\beta$-catenin levels. This may explain why previous studies failed to confirm the activation of the Wnt canonical signaling pathway in pituitary adenomas (36). Correlation analysis confirmed the existence of an inverse correlation between sFRP2 expression and 
activation of the Wnt canonical signaling pathway, including nuclear accumulation of $\beta$-catenin and overexpression of DVL-3, c-Myc and cyclin D1. These findings are consistent with those from other studies, which also reported a similar inverse correlation between the above proteins in endometrial, ovarian and breast cancer $(37,38)$. The present findings, together with those from previous studies, suggest that sFRP2 may act as a tumor suppressor through its interaction with the Wnt canonical signaling pathway by modulating the cellular cytosolic pool of $\beta$-catenin (22). However, this causality is not completely clear yet; thus, future in vitro experiments where sFRP2 is knocked down are required to confirm this causality.

The results of the present study demonstrated that there was a progressive loss in the levels of sFRP2 from normal pituitary tissues to non-aggressive NFPAs and aggressive NFPAs. This sFRP2 expression pattern in normal pituitary tissues, non-aggressive and aggressive NFPAs suggests that sFRP2 may be used as a possible surrogate marker for NFPAs progression and prognosis prediction. However, further analysis is required, in addition to follow-up studies, in order to confirm these observations.

In conclusion, the present study has demonstrated for the first time that sFRP2 expression is inversely correlated with the aggressiveness of NFPAs. sFRP2, as a tumor suppressor, may interact with the Wnt canonical signaling pathway by modulating the cellular cytosolic pool of $\beta$-catenin, and the expression of sFRP2 may serve as a biomarker for NFPAs aggressiveness and prognosis.

\section{Acknowledgements}

The present study was supported by the National Natural Science Foundation of China (Beijing, China; grant nos. 30971005, 81272522 and 81072075).

\section{References}

1. Scheithauer BW, Gaffey TA, Lloyd RV, Sebo TJ, Kovacs KT, Horvath E, Yapicier O, Young WF Jr, Meyer FB, Kuroki T, et al: Pathobiology of pituitary adenomas and carcinomas. Neurosurgery 59: 341-353, 2006.

2. Korbonits M and Carlsen E: Recent clinical and pathophysiological advances in non-functioning pituitary adenomas. Horm Res 71 (Suppl 2): 123-130, 2009.

3. Saeger W, Lüdecke DK, Buchfelder M, Fahlbusch R, Quabbe HJ and Petersenn S: Pathohistological classification of pituitary tumors: 10 years of experience with the German Pituitary Tumor Registry. Eur J Endocrinol 156: 203-216, 2007.

4. Colao A, Pivonello R, Di Somma C, Savastano S, Grasso LF and Lombardi G: Medical therapy of pituitary adenomas: Effects on tumor shrinkage. Rev Endocr Metab Disord 10: 111-123, 2009.

5. Chand-Fouché ME, Colin P and Bondiau PY: Pituitary adenomas: Multimodal management and modern irradiation techniques. Cancer Radiother 16 (Suppl): S90-S100, 2012 (In French).

6. Grossman AB: The 2004 World Health Organization classification of pituitary tumors: Is it clinically helpful? Acta Neuropathol 111: 76-77, 2006.

7. Gürlek A, Karavitaki N, Ansorge $\mathrm{O}$ and Wass JA: What are the markers of aggressiveness in prolactinomas? Changes in cell biology, extracellular matrix components, angiogenesis and genetics. Eur J Endocrinol 156: 143-153, 2007.

8. Wierinckx A, Auger C, Devauchelle P, Reynaud A, Chevallier P, Jan M, Perrin G, Fèvre-Montange M, Rey C, Figarella-Branger D, et al: A diagnostic marker set for invasion, proliferation, and aggressiveness of prolactin pituitary tumors. Endocr Relat Cancer 14: 887-900, 2007.
9. Al-Shraim M and Asa SL: The 2004 World Health Organization classification of pituitary tumors: What is new? Acta Neuropathol 111: 1-7, 2006.

10. Clevers $\mathrm{H}$ and Nusse $\mathrm{R}$ : Wnt $/ \beta$-catenin signaling and disease. Cell 149: 1192-1205, 2012.

11. MacDonald BT, Tamai K and He X: Wnt/beta-catenin signaling: Components, mechanisms, and diseases. Dev Cell 17: 9-26, 2009.

12. Herr P, Hausmann G and Basler K: WNT secretion and signalling in human disease. Trends Mol Med 18: 483-493, 2012.

13. Saito-Diaz K, Chen TW, Wang X, Thorne CA, Wallace HA, Page-McCaw A and Lee E: The way Wnt works: Components and mechanism. Growth Factors 31: 1-31, 2013.

14. Polakis P: The many ways of Wnt in cancer. Curr Opin Genet Dev 17: 45-51, 2007

15. Polakis P: Wnt signaling in cancer. Cold Spring Harb Perspect Biol 4: pii.a008052, 2012

16. Cruciat CM and Niehrs C: Secreted and transmembrane wnt inhibitors and activators. Cold Spring Harb Perspect Biol 5: a015081, 2013.

17. Hrzenjak A, Tippl M, Kremser ML, Strohmeier B, Guelly C, Neumeister D, Lax S, Moinfar F, Tabrizi AD, Isadi-Moud N, et al: Inverse correlation of secreted frizzled-related protein 4 and beta-catenin expression in endometrial stromal sarcomas. J Pathol 204: 19-27, 2004.

18. O'Hurley G, Perry AS, O'Grady A, Loftus B, Smyth P, O'Leary JJ, Sheils O, Fitzpatrick JM, Hewitt SM, Lawler M and Kay EW: The role of secreted frizzled-related protein 2 expression in prostate cancer. Histopathology 59: 1240-1248, 2011.

19. Saran U, Arfuso F, Zeps N and Dharmarajan A: Secreted frizzled-related protein 4 expression is positively associated with responsiveness to cisplatin of ovarian cancer cell lines in vitro and with lower tumour grade in mucinous ovarian cancers. BMC Cell Biol 13: 25, 2012.

20. Marsit CJ, Karagas MR, Andrew A, Liu M, Danaee H, Schned AR, Nelson HH and Kelsey KT: Epigenetic inactivation of SFRP genes and TP53 alteration act jointly as markers of invasive bladder cancer. Cancer Res 65: 7081-7085, 2005.

21. Qi J, Zhu YQ, Luo J and Tao WH: Hypermethylation and expression regulation of secreted frizzled-related protein genes in colorectal tumor. World J Gastroenterol 12: 7113-7117, 2006.

22. Chung MT, Lai HC, Sytwu HK, Yan MD, Shih YL, Chang CC, Yu MH, Liu HS, Chu DW and Lin YW: SFRP1 and SFRP2 suppress the transformation and invasion abilities of cervical cancer cells through Wnt signal pathway. Gynecol Oncol 112: 646-653, 2009

23. Vézina JL, Hardy J and Yamashita M: Microadenomas and hypersecreting pituitary adenomas. Arq Neuropsiquiatr 33: 119-127, 1975 (In Portuguese).

24. Knosp E, Steiner E, Kitz K and Matula C: Pituitary adenomas with invasion of the cavernous sinus space: A magnetic resonance imaging classification compared with surgical findings. Neurosurgery 33: 610-618, 1993.

25. Zlobec I, Terracciano L, Jass JR and Lugli A: Value of staining intensity in the interpretation of immunohistochemistry for tumor markers in colorectal cancer. Virchows Arch 451: 763-769, 2007.

26. Livak KJ and Schmittgen TD: Analysis of relative gene expression data using real-time quantitative PCR and the 2(-Delta Delta C(T)) Method. Methods 25: 402-408, 2001

27. Zhao P, Wang H, Gao H, Li C and Zhang Y: Reversal of multidrug resistance by magnetic chitosan- $\mathrm{Fe}_{3} \mathrm{O}_{4}$ nanoparticle-encapsulated $\mathrm{MDR}_{1}$ siRNA in glioblastoma cell line. Neurol Res 35: 821-828, 2013.

28. Yu R, Zhong J, Li M, Guo X, Zhang $\mathrm{H}$ and Chen J: PACAP induces the dimerization of PAC1 on the nucleus associated with the cAMP increase in the nucleus. Neurosci Lett 549: 92-96, 2013.

29. Kuster DW, Merkus D, Jorna HJ, Dekkers DH, Duncker DJ and Verhoeven AJ: Nuclear protein extraction from frozen porcine myocardium. J Physiol Biochem 67: 165-173, 2011.

30. Sano M, Driscoll DR, De Jesus-Monge WE, Klimstra DS and Lewis BC: Activated wnt signaling in stroma contributes to development of pancreatic mucinous cystic neoplasms. Gastroenterology 146: 257-267, 2014.

31. Zhang Y, Morris JP IV, Yan W, Schofield HK, Gurney A, Simeone DM, Millar SE, Hoey $T$, Hebrok $M$ and Pasca di Magliano M: Canonical wnt signaling is required for pancreatic carcinogenesis. Cancer Res 73: 4909-4922, 2013. 
32. Chambers TJ, Giles A, Brabant G and Davis JR: Wnt signalling in pituitary development and tumorigenesis. Endocr Relat Cancer 20: R101-R111, 2013.

33. Li Q, Shen K, Zhao Y, He X, Ma C, Wang L, Wang B, Liu J and Ma J: MicroRNA-222 promotes tumorigenesis via targeting DKK 2 and activating the $\mathrm{Wnt} / \beta$-catenin signaling pathway. FEBS Lett 587: 1742-1748, 2013.

34. Dellinger TH, Planutis K, Tewari KS and Holcombe RF: Role of canonical Wnt signaling in endometrial carcinogenesis. Expert Rev Anticancer Ther 12: 51-62, 2012.

35. Howng SL, Wu CH, Cheng TS, Sy WD, Lin PC, Wang C and Hong YR: Differential expression of Wnt genes, beta-catenin and E-cadherin in human brain tumors. Cancer Lett 183: 95-101, 2002.
36. Elston MS, Gill AJ, Conaglen JV, Clarkson A, Shaw JM, Law AJ, Cook RJ, Little NS, Clifton-Bligh RJ, Robinson BG and McDonald KL: Wnt pathway inhibitors are strongly down-regulated in pituitary tumors. Endocrinology 149: $1235-1242,2008$

37. Cheng YY, Yu J, Wong YP, Man EP, To KF, Jin VX, Li J, Tao Q, Sung JJ, Chan FK and Leung WK: Frequent epigenetic inactivation of secreted frizzled-related protein 2 (SFRP2) by promoter methylation in human gastric cancer. Br J Cancer 97: 895-901, 2007.

38. Becker G, Kocher M, Kortmann RD, Paulsen F, Jeremic B, Müller RP and Bamberg M: Radiation therapy in the multimodal treatment approach of pituitary adenoma. Strahlenther Onkol 178: 173-186, 2002. 